\title{
СОЦИАЛЬНЫЕ ГАРАНТИИ И ЛЬГОТЫ ПО МЕСТУ РАБОТЫ: НЕСТАБИЛЬНОСТЬ И НЕУТЕШИТЕЛЬНАЯ ДИНАМИКА
}

В работе прослеживаются изменения, которые произошли за последние два десятилетия в практике предоставления социальных гарантий и льгот работникам на российских предприятиях. Анализ основывается на данных «Российского мониторинга экономического положения и здоровья населения НИУ ВШЭ (RLMS-HSE)». Данный мониторинг позволяет проследить, как менялась система социальных гарантий и льгот на российских предприятиях. Но при этом присутствует понятная ограниченность изысканий, обусловленная структурой и содержанием инструментария, в частности тем фактом, что вопрос о предоставлении социальных льгот включался не во все волны обследования. Показано, что несмотря на позитивные сдвиги в области обеспечения социально-экономических прав россиян, значительным остается число граждан, которые не могут пользоваться по месту работы обязательными социальными гарантиями, установленными законом. Кроме того, в кризисных условиях даже благополучные предприятия вынуждены идти на сокращение перечня и объема социальных благ и услуг, которыми обеспечивается персонал дополнительно к обязательным социальным гарантиям. Охват работников такими гарантиями шире в сельской местности, тогда как возможности получения дополнительных льгот и услуг выше у персонала городских предприятий. Анализ различных аспектов дифференциации уровня обеспеченности работников социальными гарантиями и льготами по месту работы (между предприятиями разных типов и видов, профессиональными группами)

Полина Михайловна Козырева- д.социол.н., первый зам. директора, Федеральный научно-исследовательский социологический центр Российской академии наук; зав. Центром лонгитюдных обследований, Институт социальной политики, Национальный исследовательский университет «Высшая школа экономики», Москва, Россия. Электронная почта: pkozyreva@isras.ru

Александр Ильич Смирнов- д.социол.н, ведущий научный сотрудник, Институт социологии Федерального научно-исследовательского социологического центра РАН, Москва, Россия. Электронная почта: smir_al@bk.ru 
выявил повышение нестабильности в оказании многих видов дополнительных социальных услуг и рост неравенства в возможностях доступа к ним на предприятиях. Различные формы социальной поддержки активнее используются на государственных предприятиях, чем на частных. При этом дополнительными социальными льготами лучше других обеспечиваются руководители, специалисты высшего и среднего уровня квалификации, а хуже всех - неквалифицированные рабочие, т.е. работники с самой низкой заработной платой. В условиях дефицита высококвалифицированной рабочей силы обеспечение сотрудников дополнительными социальными благами и услугами частично помогает решать проблему укомплектования высокотехнологичных рабочих мест специалистами с современными компетенциями, тем самым только обостряя проблему социального неравенства.

Ключевые слова: благополучие, социальные льготы, социальный пакет, социальное неравенство, RLMS-HSE

DOI: 10.17323/727-0634-2021-19-3-389-404

Исследование вопросов предоставления социальных гарантий и льгот по месту работы связано как с выяснением их роли в процессе формирования и развития социально-трудовых отношений при решении задач роста производительности труда, повышения трудовой активности, так и с определением характера и степени их влияния на благополучие работников и их семей. Изучение этих проблем расширяет представление о структуре и иерархии социальных гарантий и льгот на предприятиях, направленности и динамике их изменений, помогает выявить различия в воздействии, которое они оказывают на разные группы работников.

Основу социальных гарантий и льгот, предоставляемых по месту работы, составляют гарантии, закрепленные законом, которые расцениваются как государственные минимальные социальные стандарты, обязательные для исполнения на всей территории страны, независимо от отраслевой принадлежности и формы собственности предприятий. Одна их часть представлена общими для всех работников гарантиями, обеспечивающими социально-экономические права граждан, другая-социальными гарантиями и льготами особого рода, предоставляемыми отдельным категориям работников (инвалидам, ветеранам, женщинам, работникам опасных и вредных производств), что подчеркивает их особое положение как наиболее уязвимых групп населения.

Кроме социальных гарантий, предписанных законодательством, многие предприятия предоставляют своим сотрудникам дополнительные социальные льготы. В соответствии со сложившимися в мировой науке традициями их принято рассматривать как часть производственной системы социального обеспечения, к которой работники приобщены благодаря своей занятости в производственном процессе (Titmuss 1968). Они вклю- 
чают различные пособия и услуги дополнительно к заработной плате, направляемые на социальные нужды, но которые не закреплены в законодательном порядке и поэтому не являются обязательными (Weiner et al. 1971). Эти пособия и услуги могут быть ориентированы на определенные группы специалистов или предоставляться всем лицам, занятым в рабочем процессе, а также членам их семей (Kahn 1973). В настоящее время практически все крупные компании, в том числе и российские, рассматривают дополнительные социальные льготы как важнейший элемент заботы о нуждах персонала (Милкович, Ньюман 2005: 456), обеспечивающий в то же время рост производительности труда, укрепление корпоративной сплоченности, повышение лояльности работников и сокращение текучести кадров (Гринберг, Чубарова 2005: 107-108). Такие компании обычно реализуют специальные программы по обеспечению поддержки работников, развитию и вовлечению персонала в корпоративную культуру. Эффективно выстроенная программа помогает продвигать важные для компании ценности, стимулировать работников в том направлении, в котором необходима максимальная отдача (Колесниченко и др. 2017).

Определенный набор социальных гарантий и льгот, предоставляемых на том или ином предприятии, составляет содержание так называемого социального пакета, который используется в борьбе за нужных работников. При этом различают «стандартный социальный пакет», содержащий гарантии, которые работодатель обязан выполнять согласно требованиям законодательства, а также «конкурентный социальный пакет», включающий в себя дополнительные социальные льготы мотивационного характера, и «компенсационный социальный пакет», объединяющий льготы, предусматривающие возмещение денежных средств, потраченных работником на выполнение его служебных обязанностей (Аксенова, Коноваленко 2019).

За время постсоветского периода вся система гарантий и льгот, связанных с занятостью, претерпела колоссальные изменения. Исходя из этого, можно выделить три группы социальных гарантий и льгот, которые не только учитывают все их многообразие, но и позволяют проследить эволюцию данной системы в период становления и развития рыночных отношений в постсоветской России. К первой группе относятся «обязательные» социальные гарантии и льготы, предусмотренные законами (оплата очередного отпуска; оплата больничных листов, оплата отпуска по беременности, родам, по уходу за ребенком до трех лет и т.п.). Вторая группа включает социальные льготы, не являющиеся обязательными с точки зрения закона, но традиционно, еще с советских времен, имеющие широкое распространение (бесплатное лечение в ведомственных медучреждениях, полная или частичная оплата путевок в санатории, дома отдыха, турбазы, детские лагеря, бесплатное или льготное питание и т.п.). И, наконец, к третьей группе относятся разнообразные льготы, предоставляемые сугубо на добровольной основе и, как правило, по инициативе работодателя, 
перечень которых чрезвычайно широк и постоянно пополняется. К ним могут относиться дополнительные медицинские страховки для сотрудников и их родственников; беспроцентные кредиты для строительства или ремонта жилья; оплата арендуемого жилья; предоставление служебного автомобиля; оплата занятий для укрепления здоровья; мобильная связь, интернет; корпоративные мероприятия и т.п.

Сегодня и предприниматели, и руководители государственных предприятий стремятся придать производству большую «гибкость», в том числе в области социально-трудовых отношений. Это в условиях не снижающейся в России остроты всего комплекса экономических и социальных проблем повышает интерес исследователей и практиков к поиску более совершенных моделей взаимоотношений в сфере труда, путей дальнейшего развития социальных услуг и пособий на предприятиях с учетом особенностей различных категорий работников. Особый интерес вызывает выяснение характера влияния таких льгот на социальное неравенство, учитывая, что работники получают через занятость разные преимущества. Как подчеркивает Лоис Брайсон, социальные льготы, предоставляемые по месту работы в денежной и натуральной форме, дают лицам, получающим заработную плату, ту или иную прибавку к их заработку, имея в виду долю в прибылях как средство повышения благосостояния работников (Bryson 1992: 131). В этой связи возникает вопрос: ведут ли льготы, предоставляемые в дополнение к доходам в виде заработной платы, к улучшению благосостояния всех работников или повышают благосостояние только некоторой части занятых?

В данной статье мы фокусируем внимание на анализе тенденций, характеризующих изменения в практике представления социальных гарантий и льгот на предприятиях, а также их влияния на социальное благосостояние различных групп занятых. Предмет анализа рассматривается в контексте проблем адаптации работников к переменам в социальноэкономической сфере и меняющимся условиям труда. Анализ опирается на данные «Российского мониторинга экономического положения и здоровья населения НИУ ВШЭ (RLMS-HSE)», который проводится с 1994 г. RLMS$H S E$ - это лонгитюдное (панельное) обследование домохозяйств на базе вероятностной стратифицированной многоступенчатой территориальной выборки, разработанной при участии ведущих мировых экспертов (см., Kozyreva et al. 2016). Данный мониторинг позволяет проследить, как менялась система социальных гарантий и льгот на российских предприятиях в последние два десятилетия. Но при этом присутствует понятная ограниченность изысканий, обусловленная структурой и содержанием инструментария. Вопрос «Предоставляются ли вам на этой работе следующие социальные льготы...?» включался в опросные документы в 2000-2010 гг. и в 2018 г. Для иллюстрации результатов сравнительного анализа отобраны данные за 2000 г. $(\mathrm{N}=3308), 2006$ г. $(\mathrm{N}=4400), 2010$ г. $(\mathrm{N}=7183)$ и 2018 г. 
(N=4627). Более детальный анализ данных, охватывающих 2000-2010-е гг., представлен ранее (Козырева 2006; Козырева и др. 2013: 116-133).

\section{Тенденции изменений в практике предоставления социальных гарантий и льгот по месту работы}

Наибольшие изменения в системе социальных гарантий и льгот по месту работы, пришлись на 1990-е гг. при переходе от плановой к рыночной экономике. В этот период произошло значительное сокращение «незарплатной» составляющей затрат на рабочую силу и резкое уменьшение числа работников, получающих социальные льготы. Только за 1992-1995 гг. охват работников такими услугами и благами сократился по различным их видам на 5-30\%; количество объектов социального назначения, находящихся на балансе предприятий, в 1990-е гг. уменьшилось на $90 \%$ (Гимпельсон, Капелюшников 2007: 46-47). Стремительно сократилось число предприятий, предоставляющих работникам те или иные привилегии. С наибольшей вероятностью социальные льготы обеспечивали главным образом благополучные крупные предприятия в промышленности и на транспорте (Кабалина, Кларк 1999: 74-77). Льготы, предоставляемые на регулярной основе, стали все чаще заменяться менее затратными единовременными денежными выплатами (Московская 2007: 298-299).

В дальнейшем отказ предприятий и организаций от предоставления своим работникам социальных гарантий и льгот продолжился, но уже не такими быстрыми темпами, что хорошо иллюстрируют данные RLMSHSE (табл. 1). Единственной областью, где наблюдалась стабилизация, явился комплекс обязательных социальных гарантий и льгот, регулируемых законами. Но при этом немалая часть работников до сих пор лишена возможности пользоваться ими, что свидетельствует о сохраняющемся неблагополучии в области обеспечения социально-экономических прав граждан. Сегодня каждому седьмому работнику по месту основной работы не оплачиваются очередные отпуска или больничные листы, а каждый четвертый трудится на предприятии, где не оплачиваются отпуска по беременности, родам, по уходу за ребенком до трех лет.

Что касается льгот, не являющихся обязательными с точки зрения закона, то за редким исключением охват ими персонала предприятий заметно сузился. Но одновременно наблюдалась и другая тенденция, свидетельствующая о расширении разнообразия дополнительных социальных льгот, которые могут включаться в социальный пакет. Наиболее активно этот процесс шел на новых предприятиях в 2000-2007 гг., т.е. в период интенсивного восстановительного роста, когда российская экономика представляла собой мозаику из осколков советской промышленности и увеличивающихся островков новой рыночной экономики (Сардарян и др. 2008). В некоторых секторах наблюдались значительные сдвиги, 
свидетельствующие об укреплении системы социальных льгот и услуг на отдельных предприятиях, которые были продиктованы прагматическими мотивами - необходимостью укрепления конкурентных преимуществ на рынках товаров и рабочей силы, сокращения социальных издержек и решения острых кадровых проблем (Московская 2007). Но в целом существующие практики предоставления социальных льгот по месту работы носили «эклектичный, несистематизированный характер», сочетая традиционные черты советской социальной политики промышленного управления и инноваций (Плотникова 2005).

Таблииа 1

Предоставление социальных гарантий и льгот работникам предприятий и организаций на основной работе, 2000-2018 гг. (в \%)

\begin{tabular}{|c|c|c|c|c|}
\hline \multirow{2}{*}{ Социальные льготы } & \multicolumn{4}{|c|}{ Год } \\
\hline & 2000 & 2006 & 2010 & 2018 \\
\hline Оплата очередных отпусков & 91,2 & 88,2 & 89,5 & 87,7 \\
\hline Оплата больничных листов & 91,1 & 84,8 & 87,2 & 85,6 \\
\hline $\begin{array}{l}\text { Оплата отпуска по беременности, родам, по уходу } \\
\text { за ребенком до трех лет }\end{array}$ & 89,1 & 76,2 & 73,6 & 73,5 \\
\hline $\begin{array}{l}\text { Бесплатное лечение в ведомственных медицин- } \\
\text { ских учреждениях, полная или частичная оплата } \\
\text { лечения в других медицинских учреждениях }\end{array}$ & 37,7 & 25,8 & 20,0 & 16,6 \\
\hline $\begin{array}{l}\text { Полная или частичная оплата путевок в санато- } \\
\text { рии, дома отдыха, турбазы, детские лагеря }\end{array}$ & 44,2 & 31,2 & 21,9 & 15,8 \\
\hline $\begin{array}{l}\text { Бесплатное содержание детей в ведомственных } \\
\text { дошкольных учреждениях, полная или частичная } \\
\text { оплата содержания детей в других дошкольных } \\
\text { учреждениях }\end{array}$ & 13,5 & 6,0 & 3,8 & 3,1 \\
\hline $\begin{array}{l}\text { Бесплатное или льготное питание, оплата } \\
\text { питания }\end{array}$ & 14,9 & 14,2 & 10,2 & 9,5 \\
\hline Дотации на транспорт, оплата проездных & 14,4 & 12,0 & 9,8 & 8,1 \\
\hline Оплата мобильной связи, интернета & $*$ & $*$ & * & 4,5 \\
\hline Обучение за счет предприятия & 20,7 & 24,6 & 21,5 & 22,6 \\
\hline $\begin{array}{l}\text { Предоставление ссуд, кредитов для строительства } \\
\text { или ремонта жилья, скидок на строительные } \\
\text { материалы }\end{array}$ & 14,0 & 10,0 & 4,1 & 2,5 \\
\hline Оплата арендуемого жилья & $*$ & 2,2 & 1,9 & 1,7 \\
\hline
\end{tabular}

*Сведения по данной позиции не собирались. 
После глобального финансово-экономического кризиса 2008-2009 гг. позитивные процессы в развитии системы социальных услуг по месту работы существенно замедлились. Следующие один за другим экономические кризисы заставили многие компании менять свои бизнес-модели и увеличивать нагрузку на персонал без повышения зарплаты. Работодатели рьяно занялись оптимизацией производства, сокращая издержки, что привело к уменьшению объема дополнительных социальных льгот по месту работы и сужению охвата ими сотрудников. Но на отдельных предприятиях обстоятельства складывались по-разному. В частности, немало таких примеров, когда работодателям в условиях кризиса удавалось не только сохранить, но и расширить перечень льгот, сделать его более разнообразным и нестандартным; обеспечить баланс целей- усилить мотивацию сотрудников за счет специфических социальных льгот и одновременно оптимизировать затраты на социальный пакет (Долгополова 2015).

В непростых экономических условиях продолжилось ослабление практики предоставления льгот на предприятиях, не являющихся обязательными, но получившими широкое распространение с советских времен. В целом за 2000-2018 гг. доля работников, которые имели возможность пользоваться на основной работе бесплатными услугами в ведомственных медицинских учреждениях, полной или частичной оплатой лечения в других медучреждениях, последовательно уменьшилась более чем вдвое- с 37,7 до 16,6\% (табл. 1). Еще более значительным оказалось сокращение доли работников, которые обеспечивались по месту работы такими социальными льготами и услугами, как полная или частичная оплата путевок в санатории, дома отдыха, на турбазы, в детские лагеря (с 44,2 до 15,8\%), бесплатное содержание детей в ведомственных дошкольных учреждениях, полная или частичная оплата пребывания детей в других дошкольных учреждениях (c 13,5 до $3,1 \%$ ). И в то же время не столь значительно у работников сократились возможности получать бесплатное или льготное питание (с 14,4 до 8,1\%).

Неизменно высокой оставалась только готовность работодателей идти на издержки, связанные с повышением уровня профессиональной квалификации работников. Несмотря на тяжелую экономическую ситуацию, ежегодно примерно каждый четвертый-пятый работник заявляет о том, что у них практикуется обучение персонала за счет предприятия. Чаще пользуются такой возможностью женщины. Этот перевес образуется большей частью за счет преобладания женщин в таких отраслях экономики, как образование и здравоохранение, где требования к повышению уровня профессиональной квалификации персонала всегда высоки. Так, по данным последней волны мониторинга, при наличии численного женского доминирования в сфере образования, доля женщин, охваченных корпоративным обучением, в полтора раза превысила соответствующую долю мужчин (31,9\% против 20,8\%), а в здравоохранении эта разница достигла двух раз (37,3\% против $18,2 \%)$. 
Остальные дополнительные льготы используются гораздо реже и охват ими работников в кризисных условиях сокращается. Нередко работодатели отказываются от принятых ранее обязательств по обеспечению сотрудников такими льготами, понимая, что негативных последствий для них это иметь не будет. Так, доля респондентов, занятых на предприятиях, где практикуются дотации на транспорт или оплачиваются проездные, за 2000-2018 гг. последовательно уменьшилась почти в два раза-с 14,4 до 8,1\%. Еще более значительным оказалось сжатие в отношении предоставления ссуд, кредитов для строительства или ремонта жилья, скидок на строительные материалы (с 14 до 2,5 \%). Не получила широкого распространения на предприятиях практика оплаты мобильной связи, интернета и арендуемого жилья.

В сельской местности охват работников обязательными льготами в целом выше, чем в городах, но в то же время в региональных центрах шансы на получение обязательных гарантий на предприятиях ниже, чем в других городских поселениях. Что касается дополнительных социальных льгот, то на протяжении анализируемого периода шансы на их получение у городских работников были выше, чем у сельских. Но дистанция между городскими и сельскими предприятиями по охвату персонала многими видами льгот заметно сократилась, а по некоторым показателям практически исчезла. Так, если в 2000 г. доля работников, которые могли проходить обучение за счет предприятия, в городах была более чем в два раза больше, чем в сельских поселениях (14,6\% против 6,4\%), то в 2018 г. эта дистанция стала едва заметной (22,7\% против 22,2\%). Значительным остается превосходство горожан над сельчанами только по уровню обеспеченности льготным медобслуживанием и транспортными услугами.

Таким образом, анализ данных мониторинга выявил значительное сужение охвата работников российских предприятий дополнительными льготами и сжатие объема социальных услуг и компенсаций по месту работы в течение последних двух десятилетий, что явилось одной из причин дальнейшего сокращения «незарплатной» составляющей в структуре затрат на рабочую силу. Свой вклад в формирование данных тенденций и структурных особенностей вносит территориальная неоднородность экономического развития и различия между типами поселений. Эти выводы находят подтверждение в других исследованиях, которые, в частности, показывают, что анализ динамики доли социальных выплат, произведенных российскими компаниями в структуре валового внутреннего продукта, и структуры издержек на рабочую силу свидетельствует о значительном сокращении социальных выплат на предприятиях (Федорова 2015). Но сами работники продолжают рассматривать хорошее социальное обеспечение на предприятии как одно наиболее весомых условий, влияющих на выбор рабочего места: 33,2\% опрошенных считают его «очень важной» и еще 40,1 \% «важной» стороной своей трудовой деятельности. 


\section{Особенности дифференциации социальных гарантий и льгот по месту работы}

Отмеченные выше тенденции, обусловленные сокращением социальной поддержки персонала, характерны как для государственных, так и для частных (полностью или с государственным участием) предприятий (Приложение, табл. 2). Причем, как и прежде, на предприятиях государственного сектора различные формы социальной поддержки работников используются активнее, чем на частных. Руководители многих частных компаний нередко отдают предпочтение выплате более высокой зарплаты, позволяющей работникам самостоятельно приобретать необходимые им услуги и блага, исходя из своих потребностей, интересов, приоритетов. Такой подход во многом совпадает с интересами работников, которые в условиях кризисной неопределенности и нестабильности демонстрируют стремление к максимизации текущего заработка. Хорошо видно и то, что предприятия, владельцами или совладельцами которых являются иностранные фирмы или иностранные частные лица, чаще, чем негосударственные предприятия предоставляют персоналу как обязательные, так и дополнительные (традиционные и новые) социальные услуги, пособия, компенсации.

Дальнейший анализ показал, что дополнительные социальные льготы чаще становятся источником повышения благосостояния работников с более высокими доходами. Об этом свидетельствует, в частности, рост уровня обеспеченности респондентов льготами на основной работе по мере повышения их профессионального статуса. Причем чаще других располагают приоритетными возможностями не только для увеличения своей заработной платы, но и для получения различных видов социальной поддержки по месту работы лица, занимающие руководящие должности, наиболее ценные специалисты с современными компетенциями, обладающие уникальными знаниями, навыками и умениями. Не менее убедительно доказывают сформулированный вывод и данные об обеспеченности дополнительными льготами респондентов из разных доходных групп (табл. 3). Для иллюстрации все респонденты распределены по четырем группам, различающимся по величине дохода от трудовой деятельности: низкодоходные слои- 0,75 или менее медианного значения; нижние среднедоходные слои- более 0,75-1,25 медианы; верхние среднедоходные слои- более 1,25-2 медианы; высокодоходные слои- более двух медианных значений.

Владимир Мау в интервью журналу «Эксперт» заметил, что в развитых странах «рост неравенства сопровождается общим ростом благосостояния, и неравенство формируется не потому, что одни беднеют, а другие богатеют, а потому, что все богатеют, но разными темпами» (Быкова 2020:46). В то же время могут появляться значимые когорты людей, чье благосостояние не растет. Но в России ситуация такова, что углубление неравенства становится результатом концентрации богатства 
у наиболее обеспеченных и обеднения наименее состоятельных групп населения. При этом нынешняя практика обеспечения работников дополнительными социальными льготами по месту работы способствует углублению этого неравенства. Льготами, предоставляемыми в дополнение к доходам в виде заработной платы, чаще всего могут пользоваться работники с высокими заработками, тогда как около 55 \% занятых практически полностью лишены такой возможности.

Таблицуа 3

Обеспеченность респондентов из разных доходных групп дополнительными социальными льготами по месту работы, 2018 г. (в \%)

\begin{tabular}{l|r|r|r|r}
\hline \multicolumn{1}{c|}{ Социальные льготы } & \multicolumn{3}{|c}{ Доходные слои } \\
\cline { 2 - 5 } & & & \\
& & & \\
& & & \\
Бесплатное лечение в ведомственных медицинских & & & \\
учреждениях, полная или частичная оплата лечения & 10,4 & 15,5 & 22,3 & 30,6 \\
в других медицинских учреждениях & & & \\
Полная или частичная оплата путевок в санатории, дома & 9,6 & 16,1 & 21,5 & 25,9 \\
отдыха, турбазы, детские лагеря & & & \\
Бесплатное содержание детей в ведомственных & & & \\
дошкольных учреждениях, полная или частичная & & & \\
оплата содержания детей в других дошкольных & & & \\
учреждениях & 2,4 & 2,9 & 4,2 & 5,1 \\
Бесплатное или льготное питание, оплата питания & 7,6 & 10,1 & 11,1 & 11,4 \\
Дотации на транспорт, оплата проездных & 4,3 & 8,9 & 11,5 & 12,4 \\
Оплата мобильной связи, интернета & 1,2 & 4,1 & 6,7 & 12,1 \\
Обучение за счет предприятия & 15,7 & 22,4 & 30,7 & 33,5 \\
Предоставление ссуд, кредитов для строительства или & & & \\
ремонта жилья, скидок на строительные материалы & 0,9 & 2,2 & 3,7 & 6,3 \\
Оплата арендуемого жилья & 0,8 & 1,1 & 2,6 & 4,4 \\
\hline
\end{tabular}

\section{Заключение}

В ходе исследования выявлено продолжающееся сокращение практики предоставления социальных гарантий и льгот по месту работы, которое затронуло различные виды и типы предприятий. В сложных экономических условиях значительно уменьшились не только объем этих социальных 
услуг и благ, но и охват ими работников предприятий. В результате заметно снизились их доля в структуре затрат на рабочую силу и вклад в формирование вознаграждения работников.

Сокращение социальной поддержки персонала при отсутствии роста заработной платы ведет к снижению уровня материального благосостояния работников и их семей, усугубляя проблемы бедности и социально-экономического неравенства. Серьезность этих проблем и острота их восприятия связаны не только с дифференциацией заработков, но и с неравным доступом к таким дополнительным ресурсам как социальные льготы, способствующие повышению качества жизни работников и членов их семей. В связи с этим особую значимость сегодня приобретает повышение внимания как к проблемам обеспечения социально-экономических прав россиян, сокращения неправовых практик в сфере труда, совершенствования политики в области качества трудовой жизни, так и к вопросам формирования более эффективных и справедливых механизмов вознаграждения работников, в том числе в области предоставления социальных гарантий и льгот по месту работы.

\section{Выражение признательности}

В данной статье использованы результаты проектов, выполненных в рамках Программы фундаментальных исследований НИУ ВШЭ.

\section{Список источников}

Аксенова А.А., Коноваленко И.Е. (2019) Особенности учета затрат на предоставление социального пакета работникам организации. Вестник Евразийской науки. Доступно по ссылке https://esj.today/PDF/88ECVN219.pdf (дата обращения: 15 января 2020).

Быкова Н. (2020) Работа над ошибками. Эксперт, (7): 42-46.

Гимпельсон В.Е., Капелюшников В.Е. (ред.) (2007) Заработная плата в России: эволюичя и дифференциащия. М.: Изд. дом ГУ ВШЭ.

Гринберг Р.С., Чубарова Т.В. (ред.) (2005) Теория и методология исследований социальных проблем. М.: Наука.

Долгополова И. В. (2015) Эффективность фирменного социального пакета: мнение сотрудников. Научный журнал НИУ ИТМО. Серия «Экономика и экологический менеджмент», (1): 48-54.

Кабалина В., Кларк С. (1999) Новый частный сектор: занятость и трудовые отношения. В. Кабалина, С. Кларк (ред.) Занятость и поведение домохозяйств: адаптация к условиям переходной экономики России. М.: РОССПЭН: 19-107.

Козырева П. М. (2006) Новые тенденции в практике предоставления социальных гарантий и льгот на предприятии. Л. М. Дробижева (ред.) Россия реформирующаяся: Ежегодник-2005. М.: Институт социологии РАН: 61-84. 
Козырева П. М., Низамова А.Э., Смирнов А.И. (2013) Ресурсы и практики соииально-экономической адаптации населения России. М.: Новый хронограф.

Колесниченко Е. А., Радюкова Я. Ю., Пахомов Н.Н. (2017) Совершенствование системы льгот и компенсаций в системе реализации социальной политики организации. Международный научно-исследовательский журнал, 64 (10/2): 99-102.

Милкович Дж.Т., Ньюман Дж.М. (2005) Система вознаграждений и методы стимулирования персонала. М.: Вершина.

Московская А. А. (2007) Рынок как фактор возрождения советских форм предоставления социальных льгот и услуг работникам промышленных предприятий. Журнал исследований социальной политики, 5 (3): 295-318.

Плотникова Е.В. (2005) Социальная политика современных российских предприятий: традиции и инновации. Журнал исследований социальной политики, 3 (3): 397-408.

Сардарян А., Комарова Т., Хожемпо В. (2008) Мотивационная функция социального пакета: чем заинтересовать работника XXI века? Управление персоналом. Доступно по ссылке: https://www.top-personal.ru/issue.html?1557 (дата обращения: 20 ноября 2019).

Федорова Е.П. (2015) Особенности социальных выплат на российских предприятиях в современный период. Baikal Research Journal. Доступно по ссылке: http://brjbguep.ru/reader/article.aspx?id=20390 (дата обращения: 25 января 2020).

Bryson L. (1992) Welfare and the State: Who Benefits? London: Macmillan.

Kahn A. J. (1973) Social Policy and Social Services (chap 3). New York: Random House.

Kozyreva P., Kosolapov M., Popkin B. (2016) Data Resource Profile: The Russia Longitudinal Monitoring Survey - Higher School of Economics (RLMS-HSE) Phase II: Monitoring the Economic and Health Situation in Russia, 1994-2013. International Journal of Epidemiology, 45 (2): 395-401.

Titmuss R. M. (1968) Commitment to Welfare. New York: Pantheon Books.

Weiner H. J., Akabas S. H., Kremen E. (1971) The World of Work and Social Welfare Policy. New York: Industrial Social Welfare Center, Columbia University School of Social Work. 


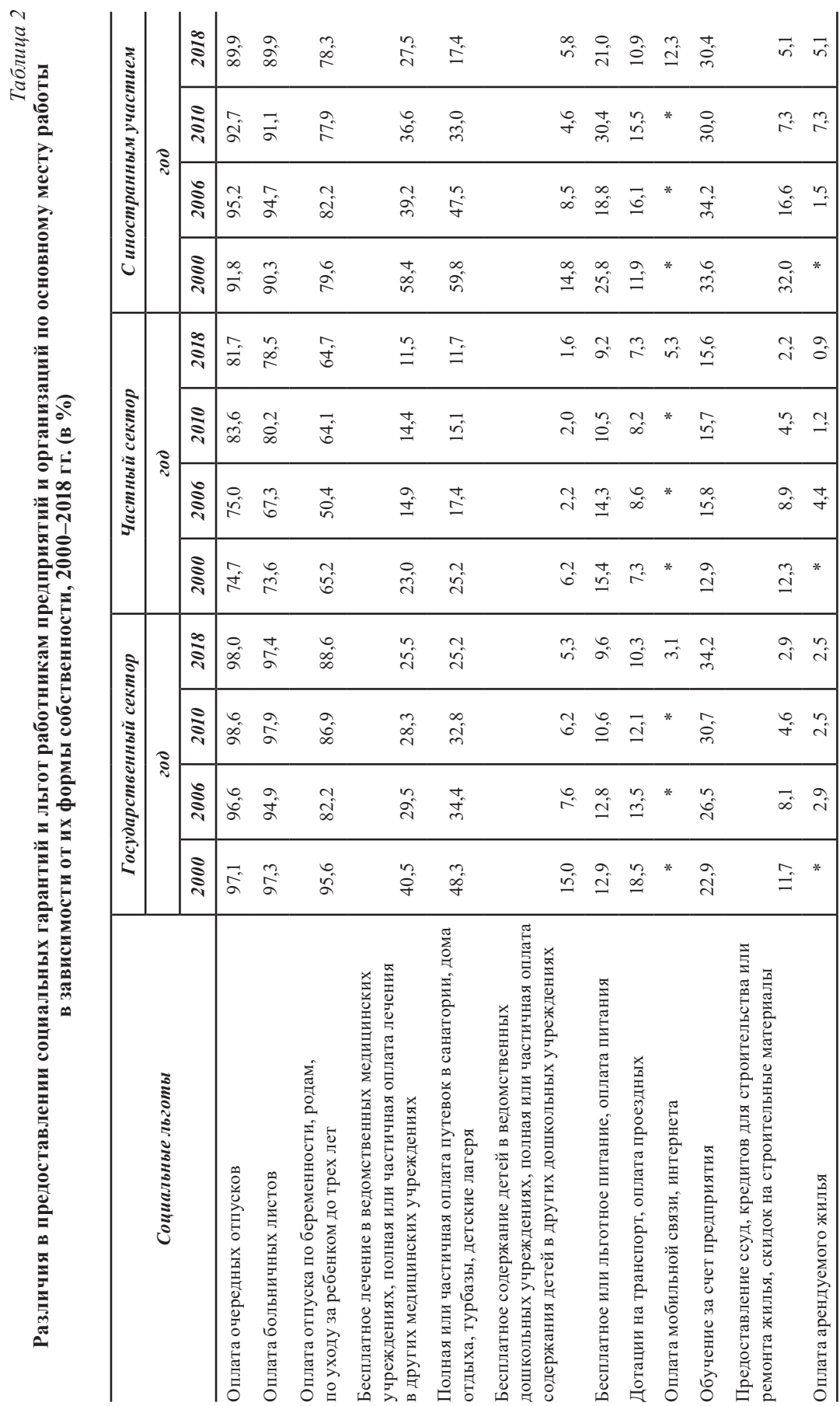


Polina Kozyreva, Aleksandr Smirnov

\section{SOCIAL GUARANTEES AND BENEFITS AT THE WORKPLACE: INSTABILITY AND UNPROMISING DYNAMICS}

This article tracks changes to social guarantees and benefits for Russian workers over the last two decades. The analysis is based on data from the 'Russia Longitudinal Monitoring Survey' (RLMS-HSE) which tracks how the system of social guarantees and benefits at Russian enterprises changes over time. Important limitations to this monitoring system should be noted, such as the structure and content of the survey documents, and that questions about social benefits provision were not asked in all the versions of the survey. It was revealed that, despite positive shifts when it comes to ensuring social and economic rights, a considerable amount of the population still cannot take advantage of the social guarantees which they are entitled to by law. Furthermore, given conditions of economic crisis, even relatively prosperous enterprises and organizations have been forced to withdraw some of the social benefits and services which they provide to their personnel in addition to mandatory social guarantees. Workers in rural areas are more comprehensively covered in terms of mandatory social guarantees, while employees at urban-based enterprises and organizations are provided with more opportunities in provision of additional benefits and services. After analysing various aspects of differentiation in terms in the provision of social guarantees and benefits to employees at the workplace, we discovered an increase in instability with regards to many additional social benefits and services as well as growing inequality in access to such benefits at enterprises. Government enterprises tend to implement various forms of additional social assistance more actively than private companies. However, it is executives and specialists of high or middle qualification who are provided with most additional social benefits and services, while unskilled workers are provided with the least benefits. Given a lack of highly skilled workers, providing employees with additional social goods and services somewhat helps to fill high-tech job positions with specialists who are up to date in their training, which in addition only exacerbates social inequality.

Key words: prosperity, social benefits, benefits package, social inequality, RLMS-HSE

DOI: 10.17323/727-0634-2021-19-3-389-404

Polina M. Kozyreva- Dr. Sci. (Sociol.), First Deputy Director of the Federal Center of Theoretical and Applied Sociology of the Russian Academy of Sciences; Head of the Center for Longitudinal Studies at the Institute for Social Policy of the National Research University Higher School of Economics, Moscow, Russian Federation. Email: pkozyreva@isras.ru

Aleksandr I. Smirnov - Dr. Sci. (Sociol.), Senior researcher, Institute of Sociology of the Federal Center of Theoretical and Applied Sociology of the Russian Academy of Sciences, Moscow, Russian Federation. Email: smir_al@bk.ru 


\section{References}

Aksenova A. A., Konovalenko I.E. (2019) Osobennosti ucheta zatrat na predostavleniye sotsial'nogo paketa rabotnikam organizatsii [Features of Cost Accounting for the Provision of a Social Package to Organization Workers]. Vestnik Yevraziyskoy nauki [The Eurasian Scientific Journal]. Available at: https://esj. today/PDF/88ECVN219.pdf (accessed 15 January 2020).

Bykova N. (2020) Rabota nad oshibkami [Work on Errors]. Expert [Expert], (7): 42-46.

Bryson L. (1992) Welfare and the State: Who Benefits? London: Macmillan.

Dolgopolova I. V. (2015) Effektivnost' firmennogo sotsial'nogo paketa: mneniye sotrudnikov [Efficiency of a Firm Social Package: Opinion of Employees]. Nauchnyy zhurnal NIU ITMO. Seriya 'Ekonomika i ekologicheskiy menedzhment' [Scientific Journal NRU ITMO. Series 'Economics and Environmental Management'], (1): 48-54.

Fedorova E.P. (2015) Osobennosti sotsial'nykh vyplat na rossiyskikh predpriyatiyakh v sovremennyy period [Features of Welfare Payments in Russian Companies in the Modern Period]. Baikal Research Journal. Available at: http://brj-bguep.ru/reader/article.aspx?id=20390 (accessed 20 January 2020).

Gimpelson V.E., Kapelyushnikov R I. (eds.) (2007) Zarabotnaya plata v Rossii: evolyutsiya i differentsiatsiya [Wages in Russia: Evolution and Differentiation]. Moscow: House of the Higher School of Economics.

Greenberg R. S., Chubarova T. V. (eds.) (2005) Teoriya i metodologiya issledovanij social'nykh problem [Theory and Methodology of Research of Social Problems]. Moscow: Nauka.

Kabalina V., Clark S. (1999) Novyy chastnyy sektor zanyatosti i trudovye otnosheniya [New Private Sector: Employment and Labor Relations]. In: V. Kabalina, S. Clark (eds.) Zanjatost' i povedenie domokhozyaystv: adaptatsiya $k$ usloviyam perekhodnoy ekonomiki Rossii [Employment and Behavior of Households: Adaptation to the Conditions of the Transitional Economy of Russia]. Moscow: ROSSPEN: 19-107.

Kahn A. J. (1973) Social Policy and Social Services (chap 3). New York: Random House.

Kolesnichenko E. A., Radyukova Ya.Yu., Pakhomov N. N. (2017) Sovershenstvovanie sistemy l'got i kompensatsiy v sisteme realizatsii sotsial'noy politiki organizatsii [Improvement of the System of Benefits and Compensations in the System of Implementation of the Social Politics of the Organization]. Mezhdunarodnyy nauchno-issledovatel'skiy zhurnal [International Research Journal], 64 (10/2): 99-102.

Kozyreva P.M. (2006) Novye tendencii v praktike predostavleniya sotsial'nykh garantiy i l'got na predpriyatii [New Trends in the Practice of Providing Social Guarantees and Benefits at an Enterprise]. In: L. M. Drobizheva (ed.) Russia that is reforming: Yearbook-2005. Moscow: Institute of Sociology, Russian Academy of Sciences: 61-84.

Kozyreva P., Kosolapov M., Popkin B. (2016) Data Resource Profile: The Russia Longitudinal Monitoring Survey- Higher School of Economics (RLMS-HSE) Phase II: Monitoring the Economic and Health Situation in Russia, 1994-2013. International Journal of Epidemiology, 45 (2): 395-401. 
Kozyreva P. M., Nizamova A.E., Smirnov A.I. (2013) Resursy i praktiki social'no-ekonomicheskoy adaptatsii naseleniya Rossii [Resources and Practices in the Socio-Economic Adaptation of the Population of Russia]. Moscow: New Chronograph.

Milkovich D. T., Newman D. M. (2005) Sistema voznagrazhdeniy i metody stimulirovaniya personala [System of Remunerations and Methods of Stimulation Personnel]. Moscow: Vershina.

Moskovskaya A.A. (2007) Rynok kak faktor vozrozhdeniya sovetskikh form predostavleniya sotsial'nykh l'got i uslug rabotnikam promyshlennykh predpriyatiy [The Market as a Factor in the Revival of Soviet Forms of Providing Social Benefits and Services to Employees of Industrial Enterprises]. Zhurnal Issledovanii Sotsial'noi Politiki [The Journal of Social Policy Studies], 5(3): 295-318.

Plotnikova E. V. (2005) Sotsial'naya politika sovremennykh rossiyskikh predpriyatiy: traditsii i novatsii [The Social Policy of Modern Russian Enterprises: Traditions and Innovations]. Zhurnal Issledovanii Sotsial'noi Politiki [The Journal of Social Policy Studies], 3 (3): 397-408.

Sardaryan A., Komarova T., Khozhempo V. (2008) Motivacionnaya funkciya social nogo paketa: chem zainteresovat' rabotnika XXI veka? [The Motivational Function of the Social Package: What Should Interest an Employee of the $21^{\text {st }}$ Century?]. Upravlenie personalom [Personnel Management]. Available at: https://www.top-personal.ru/issue. html?1557 (accessed 20 November 2019).

Titmuss R. M. (1968) Commitment to Welfare. New York: Pantheon Books.

Weiner H. J., Akabas S.H., Kremen E. (1971) The World of Work and Social Welfare Policy. New York: Industrial Social Welfare Center, Columbia University School of Social Work. 